OS AUTORES

Marcial Murciano
Professor Doutor na Universidade Autônoma de
Barcelona (Espanha). Coordenador do curso de
Doutorado em Ciências da Comunicação.
Hiliana Reis
Doutora pela Universidade Autônoma de Barcelona,
com bolsa concedida pela Fundação CAPES.
E-mail:hreisdea@ campus.ruv.itesm.mx

\title{
SOCIEDADE DA INFORMAÇÃO: POLÍTICAS DA UNIÃO EUROPÉIA
}

União Européia se mobiliza para o desenvolvimento de infra-estrutura de telecomunicação, programas de educação e novas tecnologias

A

partir dos anos 80 , e sobretudo na década de 90 , assistimos das tecnologias de informação que passaram a ocupar, em nível político, econômico e social, um lugar privilegiado no cenário mundial. A velocidade com que as mudanças trazidas pelas tecnologias avançadas de informação invadem e modificam o cotidiano das relações sociais dificulta os prognósticos a respeito de seus rumos, consequiências e estratégias de atuação. Este artigo esboça um panorama das principais características da sociedade da informação e reflete sobre as estratégias utilizadas pela União Européia (UE) ${ }^{1}$ para fazer frente aos novos desafios.

A incorporação massiva dos suportes tecnológicos produzidos pela sociedade da informação, nos mais diferentes setores do cotidiano social, vem realizando mudanças significativas na economia, na política e na cultura mundiais. Ao proporcionar novas e ilimitadas possibilidades de armazenamento, produção, aquisição e distribuição da informação, as tecnologias avançadas de informação e comunicação tornaram-se, em curto

1. Criada no princípio dos anos 50 e ratificada em 7 de fevereiro de 1992, quando foi firmado, em Maastricht, Holanda, o Tratado da União Européia, assinado pelos governos dos seguintes países-membros: Alemanha, Bélgica, Dinamarca, Espanha, França, Grécia, Irlanda, Itália, Luxemburgo, Países-Baixos, Portugal e Reino Unido. 
espaço de tempo, o eixo propulsor da sociedade atual. Através delas, novos produtos são lançados no mercado, dos quais, repentinamente, não se pode prescindir. Surgem novos modelos de consumo, comportamentos, valores e conceitos. Espaço e tempo adquirem outra dimensão: acesso imediato, diversificado e simultâneo, graças, sobretudo, às inovações trazidas pelas redes de satélites e cabos, multiplicando as possibilidades de comunicação e de acesso à informação.

As novas possibilidades trazidas pela sociedade da informação produzem como consequiência um redimensionamento do mercado, onde os tradicionais espaços territoriais cedem espaço a uma nova dinâmica econômica, conhecida como processos de mundialização e globalização.

"Frente aos enfoques tradicionais, de vinte anos atrás, através dos quais analisávamos a oposição das forças nacionais frente à emergência de uma crescente atividade exterior transnacional, o característico da atual fase é identificar, no cenário mundial, ao menos quatro espaços de atividade comunicacional, cada vez mais diferenciados" .

Segundo Murciano, os quatro espaços são: o local, com maior proximidade, referente aos entornos sociais articulados pelas comunidades históricas; o nacional, definido pelo Estado-Nação, que passa por uma fase de reestruturação; o regional ou supranacional, de recente constituição; e o global ou planetário.

\section{GLOBAL, REGIONAL, NACIONAL E LOCAL}

O mundo encontra-se diante da emergência de um novo espaço global, onde proliferam mensagens sincrônicas e possibilidades de comunicação ativa inteiramente novas. Não só são válidos os exemplos da poderosa CNN, nos Estados Unidos, ou da BBC, na Inglaterra, mas, sobretudo, o da comunicação através das redes telemáticas. Surgem, neste cenário, espaços regionais, agrupando diferentes nações em torno de interesses comuns, dentre os quais destacamos, a União Européia (UE), o Tratado de Livre Comércio (Nafta - EUA, México, Canadá) ou, na América Latina, o Mercosul. Não se pode esquecer os tradicionais espaços do Estado-Nação, que se modificam como conseqüência desse novo agrupamento. E por último os espaços locais, diferenciados por suas características específicas de língua, história, religião, costumes etc.

Oredimensionamento do planeta sob essa nova perspectiva vem provocando profundas mudanças não apenas sob os pontos de vista econômico, demográfico e tecnológico, mas, sobretudo, na esfera comunicativo-social.

A esfera comunicativo-social constitui o nexo simbólico que permite a articulação destes novos espaços mencionados.

2. MURCIANO, Marcial. Las políticas públicas de comunicación en Europa. Un análisis desde la perspectiva de los macroespacios regionales. (As políticas públicas de comunicação na Europa. Uma análise a partir da perspectiva dos macroespaços regionais.) Conferência apresentada no XIX Congresso Brasileiro de Ciências da Comunicação. (INTERCOM). Londrina (PR), 2-6 de setembro, 1996. 
Sob essa nova perspectiva, os desafios colocados pela sociedade da informação - não apenas os econômicos, como também os sóciopolíticos - vêm chamando a atenção dos Estados integrantes da União Européia (UE), no sentido de elaborar estratégias específicas para o desenvolvimento de planos conjuntos de cooperação e desenvolvimento integrado.

Com maior intensidade, a partir de 1993, governantes e destacados membros da sociedade européia, com relativa frequiência, vêm se reunindo para discutir o desenvolvimento de programas cooperativos na área das telecomunicações e telemática, nos mais diferentes ramos de atividades socioeconômicas: administração pública, telecomunicações, transporte, saúde, educação, dentre outros ${ }^{3}$.

A União Européia dirige sua atenção para os rumos e as novas possibilidades abertas pelos avanços tecnológicos e, prin- cipalmente a partir de 1990 , começa a investir maciçamente nesse setor. Inaugura-se uma nova fase de desenvolvimento e consolidação dos seus ideais políticos e econômicos, destacando-se, dentre estes, um especial interesse em fazer frente ao poderio norte-americano e japonês, o que, em outras palavras, significa colocar a área tecnológica no centro das suas atenções.

"A surpreendente velocidade com que evoluem as tecnologias de informação e comunicação produzirá uma mudança político-social de tal envergadura que já se fala de uma terceira revolução industrial, fruto da sociedade da informação. As novas tecnologias oferecem à União Européia o caminho para a solução de problemas complexos, dentre os quais se destacam o reforço do espaço econômico da Europa, a eliminação do desemprego estrutural e a melhoria da proteção ao meio ambiente" ${ }^{\text {. }}$

3. COMISIÓN DE LAS COMUNIDADES EUROPEAS (CCE). La ampliación de la Unión Europea. (A ampliação da União Européia.). Luxemburgo: Oficina de Publicaciones Oficiales de las Comunidades Europeas. CECA-CECEEA, 1994. p. 10.

Cities \& Regions. Info Way to Europe. (Cidades \& regiões. Infovia para a Europa.) Barcelona: Ajuntament de Barcelona, 1996. E-mail: infowaytoeurope@mail.bcn.es

. Conferencia Intergubernamental. Dictamen de la Comisión. Reforzar la unión política y preparar la ampliación. (Conferência intergovernamental. Ditames da Comissão. Reforçar a união política e preparar a ampliação.) Luxemburgo: Oficina de Publicaciones Oficiales de las Comunidades Europeas. CECA-CE- CEEA, 1996. p. 23.

Comunicación de la Comisión al Consejo, al Parlamento Europeo y al Comité Económico social. (Comunicação da Comissão ao Conselho, ao Parlamento Europeu e ao Comitê Econômico-Social.) Bruxelas: Oficina de Publicaciones Oficiales de las Comunidades Europeas COM (96) 392 Final, 1996.

. Estrategia a plazo medio, 1996 - 2001. (Estratégia a médio prazo, 1996-2001.) Paris: UNESCO, 1996.

News Information Society. (Notícias da sociedade da informação.) Bruxelas: Information Society Project Office (ISPO), $\mathrm{n}^{\circ} 5$, setembro, 1996.

. La sociedad de la información. (A sociedade da informação.) Luxemburgo: Oficina de Publicaciones Oficiales de las Comunidades Europeas, 1996. p. 15.

. Rapport à I'UNESCO de la Commission Internacionale sur L'Éducation pour le Vingt et Unième Siècle. (Relatório à Unesco da Comissão Internacional sobre educação para o século XXI.) Paris: UNESCO, outubro de 1996.

"Vivir y trabajar en la sociedad de la información: prioridad para las personas - Libro Verde". (Viver e trabalhar na sociedade da informação: prioridade para as pessoas - Livro verde.) Boletín de la Unión Europea. Luxemburgo: Suplemento 3, Documento redactado sobre la base del documento COM (96) 389 final. CECA-CECEEA. Oficina de Publicaciones Oficiales de las Comunidades Europeas, 1996. p. 32.

. Livre Blanc sur l'éducation et la formation. Enseigner et Apprendre vers la Société Cognitive. (Livro Branco sobre a educação e a formação. Ensinar e aprender para a sociedade cognitiva.) Bruxelas: Oficina de Publicaciones Oficiales de las Comunidades Europeas, 1996.

4. COMISIÓN DE LAS COMUNIDADES EUROPEAS. Introduction to Information Society. (Introdução à sociedade da informação.) Information Society Project Office (ISPO) (Escritório do Projeto Sociedade da Informação). Bruxelas: Oficina de Publicaciones Oficiales de las Comunidades Europeas. CECA-CE-CEEA, maio de 1995. p. 1-7. 
A vontade política de competir no mercado internacional e a crença no poder das tecnologias avançadas de comunicação fizeram com que a União Européia começasse a investir com mais força neste setor.

Medidas mais concretas foram adotadas, de modo especial, a partir do momento em que $\mathrm{Al}$ Gore, então vice-presidente dos Estados Unidos, lançou, em 1995, o National Information Infrastructure (NII) (Infra-estrutura Nacional de Informação), mobilizando não apenas o seu país como os mais fortemente industrializados em torno do desenvolvimento da infra-estrutura de comunicação.

Muitos projetos experimentais, envolvendo as autopistas de informação, começaram a ser desenvolvidos, sendo tema da reunião de cúpula do grupo dos sete países mais ricos - G-7. "Esta revolução está transformando rapidamente a economia das sociedades mais desenvolvidas, também a das menos favorecidas. As vantagens potenciais são tamanhas que precisam ser exploradas numa escala global, razão pela qual o grupo do G-7, liderando as nações mais industrializadas, organizou uma conferência ministerial em Bruxelas, em fevereiro de 1995"s.

Dada a importância adquirida pelas tecnologias de informação e comunicação no conjunto das preocupações da UE e para fazer face a esses desafios, seus Estados membros vêm desenvolvendo uma série de estratégias conjuntas, das quais pode-se destacar: o Informe Bangemann e o livro Vivir y trabajar en la sociedad de la información: prioridad para las personas ${ }^{6}$ (Viver e trabalhar na sociedade da informação: prioridade para as pessoas).

\section{UNIÃO EUROPÉIA: DESAFIOS DA TELEMÁTICA}

Em dezembro de 1990, um grupo de especialistas de alto nível e renomados representantes de distintos setores da indústria européia foram convidados para debater sobre os rumos e conseqüências desta sociedade. Martin Bangemann, comissário europeu encarregado dos Affaires Industrielles (Negócios Industriais) na comissão presidida por Jacques Delors, elaborou um relatório, publicado em maio de 1994, sob o título Europa y la sociedad global de la información ${ }^{7}$ (Europa e a sociedade global da informação).

Também conhecido como Informe Bangemann, o relatório propõe dez campos de aplicação prioritários, tendo como meta facilitar o apoio ao acesso e desenvolvimento de recursos telemáticos que promovam serviços para a melhoria da qualidade de vida dos cidadãos. Com este desafio, pretende-se "expandir as formas de acesso e conhecimento das tecnologias de informação a toda a Europa", bem

5. INFORMATION SOCIETY PROJECT OFFICE. (ISPO) (Escritório Projeto Sociedade da Informação). Bruxelas, 1995. p. 3. 6. COMISIÓN DE LAS COMUNIDADES EUROPEAS. Vivir y trabajar ... (Viver e trabalhar...) op. cit. p. 32.

7. BANGEMANN, Martin. Europa y la sociedad global de la información. Recomendaciones ao consejo europeu. (Europa e a sociedade global da informação. Recomendaçōes ao Conselho Europeu.) Bruxelas: Oficina de Publicaciones Oficiales de las Comunidades Europeas. CD-84-94-290-ES-C, 26 de maio, 1994. p. 4-36. 
como contribuir para a "expansão das redes tecnológicas tanto ao setor público quanto ao privado" 8 .

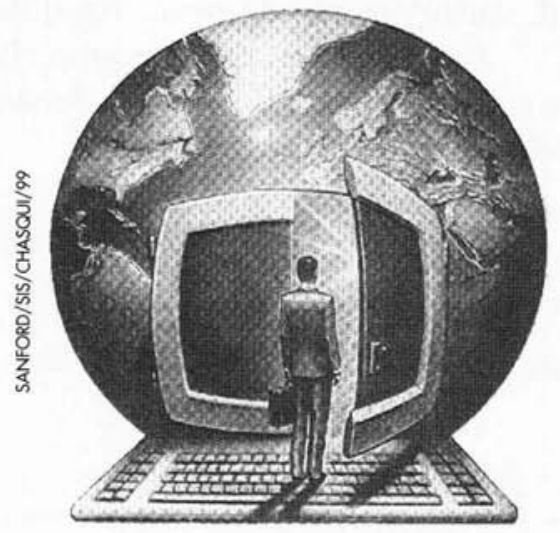

Segundo o Informe Bangemann, a Europa, preocupada em desenvolver estratégias para o desenvolvimento da sociedade da informação, "necessita neutralizar a ação dos monopólios e criar uma estrutura comum de regulamentação, com vistas à livre concorrência de mercado. A tarefa dos governos é salvaguardar a competição do mercado" ". A sua flexibilização e a cooperação de esforços e capital são outras das linhas básicas que direcionam as orientações desse relatório.

A publicação do documento Crecimiento, competitividad, empleo ${ }^{10}$ (Crescimento, competitividade, emprego) reflete a crescente preocupação da sociedade européia em relação à sociedade da informação. Em julho de 1994, a comissão presidida por Martin Bangemann apresentou o Plan de actuación. Europa en marcha hacia la sociedad de la información (Plano de atu- ação. Europa em marcha para a sociedade da informação) que contempla vários campos: jurídico e regulamentário; redes, serviços básicos, aplicações; conteúdos, aspectos sociais e culturais enfocados sob a perspectiva do desenvolvimento da sociedade da informação. Os temas centrais desse relatório dizem respeito:

a) às necessidades e desafios criados pela sociedade da informação ao mundo do trabalho;

b) à responsabilidade dos governos, administrações e sociedade civil; ao estabelecimento de estratégias para o desenvolvimento de políticas públicas e capacitação de novas habilidades para atender às novas demandas colocadas pelas tecnologias de informação;

c) ao acesso e distribuição do conhecimento.

Os temores, pode-se dizer globais, presentes em todas as sociedades que de algum modo convivem com a sociedade de informação, serviram de ponto de partida para abrir o debate desse Informe.

"As tecnologias destruirão mais empregos do que criarão? Os cidadãos serão capazes de se adaptar às novas circunstâncias? A complexidade e o custo das novas tecnologias não irão aumentar os desequilíbrios entre as zonas industrializadas e as menos desenvolvidas, entre jovens e idosos, entre os que a elas têm acesso e os outros?" Para responder a essas indagações, uma das primeiras providências da UE foi a de traçar políticas e estratégias comuns entre os seus diferentes Estados membros.

8. KLEIST, Jörgen. Cooperation for Europe.The Bangemann Challenge. (Cooperação para a Europa. O desafio Bangemann). Estocolmo: 15 de maio de 1996. E-mail: bangemann@challenge.stockholm.se

9. MARAGALL, Pascual. Cities \& regions. Info way to Europe - The Bangemann Challenge. (Cidades \& regiōes. Infovia para a Europa - (O desafio Bangemann). Barcelona: ISPO/Ajuntament/ the Bengemann Challenge, 1996.

10. CCE. La ampliación... op. cit. p. 1-8. 
Além de ser uma porta para estimular o debate, nota-se, nesse Informe, uma preocupação acentuada em relação às novas formas de organização do trabalho, ao emprego e à coesão social, já expressa no título: Prioridade para as pessoas. A extensão do conhecimento e a qualificação dos recursos humanos para atender às necessidades desta sociedade são alguns dos desafios que o Informe também tenta responder.

"Esta nova sociedade, que tem no conhecimento sua matéria-prima, precisa ser desenvolvida, entre outros aspectos, através do apoio à aquisição de novos conhecimentos, da união entre escolas e o setor empresarial, além do tratamento da formação como um investimento, da mesma forma e com a mesma importância que se dá a outras formas materiais" "I.

Nessa sociedade, a escola, que vem cedendo espaço aos meios de comunicação, agora deverá também compartilhar a responsabilidade de formação com outros atores sociais. A necessidade de ampliar a cooperação entre o setor público e o privado, entre instituições educacionais e empresas é uma orientação constante nos Informes da UE.

"Hoje, não é mais possível considerar que o papel da empresa se restringe unicamente à demanda de indivíduos quali- ficados ou a fornecer um complemento de formação. A empresa é, além do mais, uma importante produtora de conhecimentose de desenvolvimento de novas habilidades"12. Fato este que, além de propiciar uma ampliação dos espaços educacionais, implica mudanças de estratégias.

\section{O Informe da UNESCO é mais contundente. Aponta para a necessidade de uma revisão crítica dos sistemas educacionais existentes.}

Indica a ampliação das oportunidades desta área que devem ser adaptadas às circunstâncias particulares de cada sociedade. Concebe o processo educacional como uma responsabilidade da sociedade em seu conjunto, "e não apenas de alguns setores", onde colaboram o setor público e privado e, ainda, diferentes atores sociais como, por exemplo, os meios de comunicação social e as comunidades locais.

"É preciso conceber sistemas educativos alternativos, não tradicionais, de baixo custo, tanto formais como informais, a fim de atender às necessidades, não necessariamente coincidentes, das diferentes categorias de educandos"13.

\footnotetext{
11. MARÍN MARTINEZ, A. Pedro. La sociedad de la información y la educación. Experiencias de la Comisión Europea. (A sociedade da informação e a educação. Experiências da Comissão Européia.) Texto apresentado no Curso de Verão da Universidade de Alcalá - Las tecnologías de la información. Alcalá de Henares, 14 a 17 de julho, 1997. 12. DELORS, Jacques. Livre Blanc sur l'éducation et la formation. Enseigner et Apprendre vers la société cognitive. (Livro branco sobre a educação e a formação. Ensinar e aprender para a sociedade cognitiva.) Paris: UNESCO, 1996. 13. CCE. Rapport à l'UNESCO de la Comission Internacionalle sur l'éducation pour le XXI siècle (Relatório à UNESCO da Comissão Internacional sobre Educação para o século XXI.) Paris: UNESCO, outubro de 1996. Vale ressaltar o papel exercido pelos meios de comunicação, seja em relação às cadeias comerciais ou às educativas que oferecem programas variados no âmbito educacional, voltados a públicos distintos. Dentre outras, destacamos a BBC de Londres, "La Cinquième" (França), TVE (Espanha).
} 
A formação de pessoal qualificado para atuar no setor também se encontra entre as preocupações dessa sociedade.

A educação a distância passa a cumprir um papel fundamental nessa fase de transição da União Européia em direção à sociedade da informação.

Oferece novas oportunidades de formação profissional e diminui os obstáculos existentes entre as tradicionais fronteiras de tempo e espaço.

Os crescentes e altos investimentos europeus no âmbito da educação a distân$\mathrm{cia}^{14}$ e a complexidade das experiências desenvolvidas na Europa podem ajudar a compreender os rumos e as principais estratégias que vão marcar a educação do século XXI, trazendo subsídios às políticas e ao desenvolvimento de projetos de educação a distância, seja em contextos nacionais, regionais ou locais. Segundo Jacques Perriault ${ }^{15}$, a União Européia, mais especificamente a partir de 1985 , vêm unindo esforços para encorajar o desenvolvimento de projetos nesta área.

"Entre 1987 e 1992, milhares de ECUs $^{16}$ foram investidos para o financia- mento de iniciativas regionais, em programas de aproximação entre universidades e indústrias e para criar redes de cooperação entre as regiões européias. Alguns programas mais recentes voltados ao desenvolvimento de pesquisas, como por exemplo, o Leonardo e o Sócrates ampliaram os recursos dedicados a esta finalidade" 17 . O impacto financeiro dos mercados de informação são enormes. "Em 1994, estimou-se que a indústria de conteúdos de informação atingiu um nível ao redor de 150 bilhões de ECUs"18.

Para compreender o que tem sido feito na Europa, em termos educacionais, diante do contexto da sociedade da informação, vale mencionar alguns dos principais programas educacionais desenvolvidos pela União Européia:

1- O COMET, criado em 1986, tem por objetivo a formação de profissionais, o desenvolvimento e a transferência de tecnologias através da cooperação entre empresas e universidades.

2- O Task Force (Aplicações educativas de multimeios), criado em março de 1995, com o objetivo de analisar e criar condições para o desenvolvimento da indústria educativa multimídia européia.

3-O Sócrates permite a mobilidade dos estudantes europeus que queiram completar seus estudos em outro país. Enquanto,

14. Considerada como a primeira Universidade a distância européia, The Open University (Universidade Aberta) foi criada na Inglaterra em 1971, servindo de modelo às demais. Na Espanha, a Universidade Aberta de Catalunya - UOC (Universidade Aberta da Catalunha), situada em Barcelona, é considerada a primeira universidade virtual européia, inaugurada em outubro de 1995.

15. Especialista francês em Ciências da Informação e Comunicação, diretor do laboratório de pesquisa sobre a indústria do conhecimento do Centre National d' Enseignement à Distance - CNED (Centro Nacional de Ensino a Distância), situado no Futuroscope (Poitiers, França).

16. Moeda oficial da União Européia, convertida em Euro a partir de $1^{2}$ de janeiro de 1999.

17. PERRIAULT, Jacques. La communication du savoir à distance. Autoroutes de l'information et téle-savoirs. (A comunicação da educação a distância. Auto-estradas da informação e telesaberes.) Paris: L Harmattan, 1996. Nota-se que além das parcerias entre empresa e universidade, esses projetos incentivam a formação de alunos em universidades e países diferentes dos de origem. Dessa forma, beneficiam-se da aprendizagem de um novo idioma, têm acesso a diferentes fontes de formação e informação, além de conviver com outras formas de cultura.

18. MARÍN MARTINEZ, A. Pedro. La sociedad...op. cit. p. 6. 
em 1987, 300 estudantes espanhóis puderam ter acesso a uma bolsa, no período relativo a 1996/1997 esta cifra ultrapassou 10 mil. O que indica que " $70 \%$ dos universitários espanhóis que solicitam bolsa conseguem estudar no estrangeiro. Tal porcentagem coloca a Espanha em primeiro lugar da União Européia”, observa o vice-secretário geral do Conselho de Universidades, Luís Buñuel ${ }^{19}$.

4- O Leonardo da Vinci foi criado com a finalidade de desenvolver políticas de formação profissional para facilitar a integração dos cidadãos europeus. Dentre as suas prioridades encontram-se: estímulo à cooperação para a formação profissional, apoio ao intercâmbio de experiências e fomento à mobilidade de profissionais, aprendizes e estudantes para que possam adaptar-se às novas mudanças.

5- O plano de ação Aprender na sociedade da informação $o^{20}$ desenvolve-se em torno de quatro grandes linhas de ação: apoio à interconexão das redes regionais e nacionais das escolas que integram a União Européia; desenvolvimento e disseminação de conteúdos de interesse europeu; formação de professores para integrar as tecnologias de informação e de comunicação às estratégias educacionais e, finalmente, facilitar o acesso às oportunidades educativas existentes, quer seja em relação aos equipamentos audiovisuais ou a produtos multimeios.
Dentro das ações previstas por esse plano, destaca-se ainda a iniciativa Net@ days, em funcionamento desde outubro de 1997, cujos objetivos são:

- estimular o desenvolvimento e a promoção de atividades através de redes eletrônicas em estabelecimentos escolares para incentivar experiências similares em outros países, regiões e cidades da União Européia;

- estimular o uso da experiência Net@days, despertando o interesse das partes (escolas, setor acadêmico, autoridades públicas e empresas) para as vantagens da utilização da rede; melhorar a qualidade do serviço educacional e a sua operacionalidade através de Internet;

- implementar de cinco a dez redes/projetos via Internet em cada Estado membro, desenvolvendo a sinergia potencial entre as três categorias de participantes (escolas, autoridades públicas e empresas), estimulando, onde for possível, pontos de associação entre os sistemas público/privado.

\section{COOPERAÇÃO REGIONAL E TECNOLOGIA PARA EDUCAÇÃO}

Como desdobramento do Informe Bangemann, numa iniciativa pioneira da cidade de Estocolmo, Suécia, foi criado, em meados de 1990, um projeto conhecido como The Bangemann Challenge $e^{21}(\mathrm{O}$ desafio Bangemann), voltado ao desenvolvimento de experiências integradas que te-

\footnotetext{
19. BRANDIDO, Belén. Balance positivo de diez años de programas de intercambio. (Balanço positivo de dez anos de programas de intercâmbio.) Gaceta Universitaria. Barcelona, Vida Universitária, 2 de março de 1998. p. 10. 20. Comisión Europea. Plan de Acción para una iniciativa educativa Europea (1996-1998). Aprender en la Sociedad de la Información. (Plano de ação para uma iniciativa educativa européia - 1996-1998. Aprender na sociedade da informação.) Comunicação ao Parlamento Europeu. Conselho, ESC e Comitê de Regiōes, DG XXII/285/1996-EN. 21. KLEIST, Jörgen. Cooperation for Europe... op. cit,
} 
nham as tecnologias de informação como suporte. Congrega 23 grandes cidades pertencentes à UE, o que significa $10 \%$ da população dos Estados Unidos. Até 1996, congregava 99 diferentes projetos voltados às áreas definidas como prioritárias. Todos estes projetos encontram-se interconectados por redes telemáticas, o que facilita enormemente o acesso e a distribuição da informação.

As novidades trazidas pelo desenvolvimento da comunicação vêm modificando a economia de mercado transnacional, fazendo desaparecer inúmeras profissões.

Ao mesmo tempo possibilita a criação de uma série de alternativas de mercado de trabalho nas áreas de telecomunicações e de telemática.

Como líder e propulsora de uma série de projetos propostos pela União Européia no campo das telecomunicações e informática, Barcelona também integra o projeto $O$ desafio Bangemann.

Barcelona sempre ocupou um lugar de destaque no cenário europeu por sua iniciativa na utilização das novidades tecnológicas. Foi o berço da primeira fotografia feita na Espanha, pioneira na transmissão do rádio e onde se instalaram as primeiras linhas telefônicas do país. A junção de esforços públicos e privados tem permitido que essa cidade venha desenvolvendo uma série de recursos e estratégias fundamentais no campo das telecomunicações, transferência de novas tecnologias e utilização de espaços virtuais ${ }^{22}$.

Dentre estes, cabe mencionar a criação da Universidade Aberta da Catalunha, a primeira universidade virtual européia ${ }^{23}$. Trata-se de uma fundação de capital misto - estatal e privado. Além de contar com o apoio financeiro de diversas empresas privadas, é subvencionada pelo governo da Catalunha.

Também merece destaque o Projeto INFO 2000, criado pela União Européia (UE). Tem como finalidade desenvolver e estimular a indústria de conteúdos informáticos multimeios para atender aos desafios da sociedade da informação. Trata-se de um serviço oferecido pelo Information Society Project Office (ISPO) (Escritório do Projeto Sociedade da Informação) aos países membros da União Européia, através de convênios e parcerias com governos regionais, locais. O governo de Valência, através da comunidade valenciana, passou a incorporar o setor educativo às localidades que compõem o projeto Infoville, desenvolvendo o Infovillepara crianças, voltado a professores e alunos do ensino básico e secundário.

22. MARAGALL, Pascual. Cities \& regions... op. cit.

23. Por universidade virtual entende-se uma instituição cuja comunicação acontece a distância, que apresenta como suporte básico de sua estrutura comunicacional as chamadas tecnologias avançadas de informação. Portanto, depende fundamentalmente dos recursos telemáticos. 
Este projeto, "além de implicar um processo de modernização de toda a comunidade valenciana e o desenvolvimento de um conjunto de serviços interativos, facilita o uso das novas tecnologias, oferecendo informação personalizada e adaptando-se às necessidades concretas das pessoas" ${ }^{24}$.

Desenvolvendo estratégias de ensinoaprendizagem que combinam suporte impresso, CD-Rom e telemática (servidor Web), pretende estimular professores e alunos, colocando ao alcance deles as ferramentas necessárias ao desenvolvimento e utilização das tecnologias de informação e comunicação. Nas palavras de seus responsáveis, "antecipar o futuro como fonte de vantagens competitivas" 25 significa investir na formação de crianças, adolescentes e professores para prepará-los para as exigências e desafios dessa nova sociedade e para obter os benefícios que dela advêm.

Enfim, são evidentes os esforços da União Européia e dos governos regionais para proporcionar subsídios e adequar os mais diferentes setores sociais às novas necessidades trazidas pela confluência da comunicação, educação e sociedade da informação. Assiste-se a um investimento maciço no desenvolvimento e fortalecimento da infra-estrutura necessária para o desenvolvimento tecnológico: crescimento das redes automáticas que permitem o acesso imediato aos dados contidos nas autopistas eletrônicas; acesso integrado de bibliotecas virtuais, fonte vital para novas formas de acesso, intercâmbio de conhecimentos e de interação.
A análise destes relatórios

leva à conclusão de que as grandes preocupações atuais da União Européia apresentam como eixo central as tecnologias avançadas de comunicação.

O desenvolvimento de programas e de infra-estrutura para atender aos novos desafios colocados pela sociedade da informação, além de ter como objetivo uma forte vontade de competir e manter-se à frente do mercado, também demonstra uma preocupação crescente com seus cidadãos.

Ainda que a prática não acompanhe com a mesma velocidade as intenções, o fato de essas questões aparecerem como prioridade nos Informes da União Européia, caracteriza, pelo menos, uma abertura para a busca de uma nova ética política que acompanha os desafios colocados pela sociedade da informação. $\mathrm{O}$ que significa priorizar o desenvolvimento de políticas públicas que possam tirar o máximo proveito dos recursos tecnológicos e, ao mesmo tempo, assegurar o acesso e distribuição eqüitativos dos seus benefícios ao conjunto da população. Se os entraves para sua consolidação ainda são muitos, nota-se uma vontade política, através de projetos concretos, onde economia, política e bem-estar social passam a dividir espaços de forma que os cidadãos tenham prioridade.

\footnotetext{
24. Fundación Oficina Valenciana para la Sociedad de la información - OVSI. Infoville para niños. Los niños en la sociedad de la información. (Infoville para as crianças. As crianças na sociedade da informação). Alicante, 1995.

25. Fundación Oficina Valenciana para la Sociedad de la información - OVSI. Proyecto Infoville. El tránsito de la Comunidad Valenciana hacia la Sociedad de la información. Valencia, Generalitat Valenciana.E-mail: infoville@ovsi.com
} 


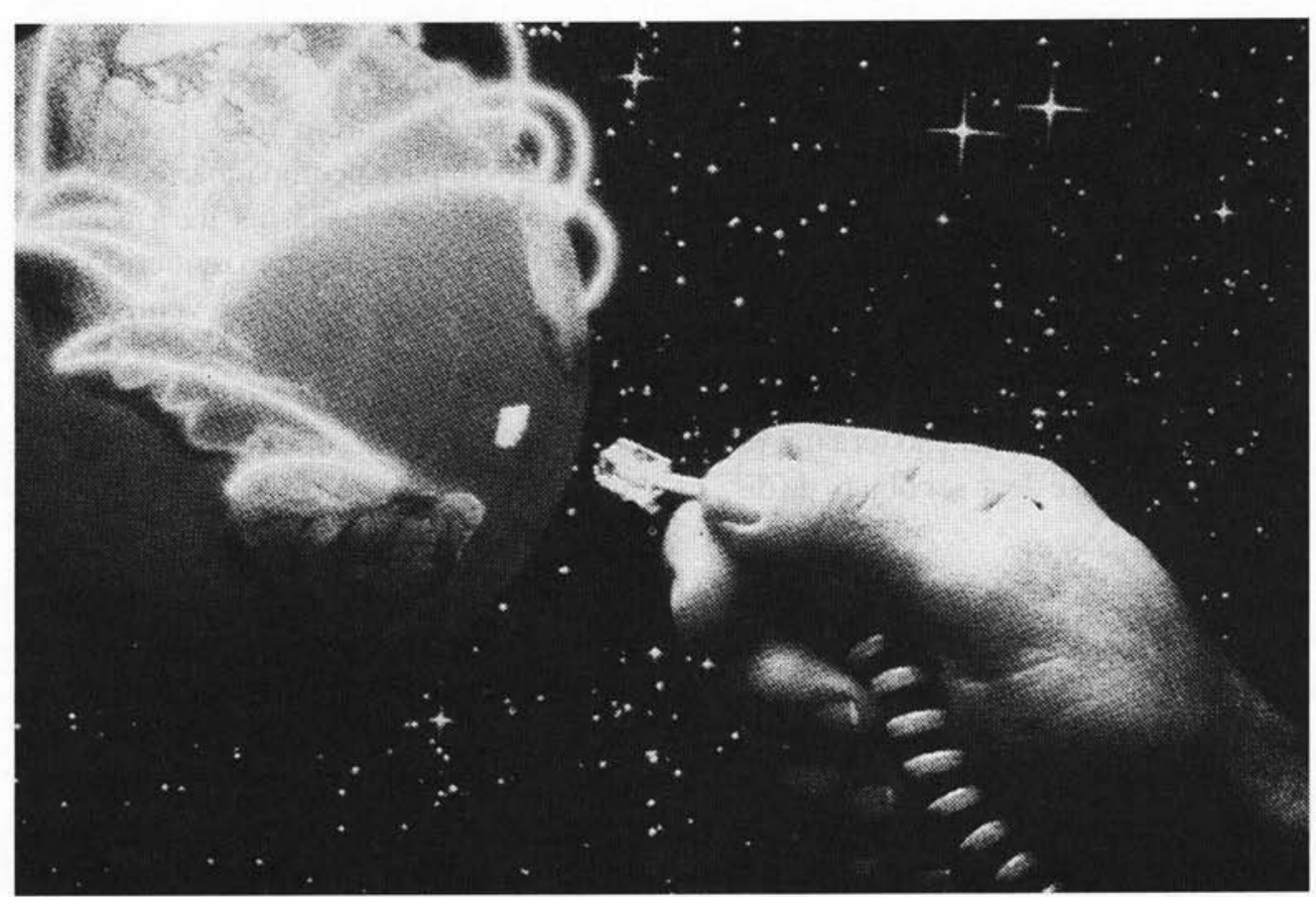

Frente ao desenvolvimento da sociedade da informação, assistimos a uma mudança do cenário mundial. Se a exclusão social de muitos em benefício de poucos é uma das premissas da cultura de mercado capitalista, nota-se que os Informes da UE apresentam maior preocupação dos seus dirigentes, ainda que seja em relação a propostas políticas globais, com o lado social, com uma distribuição mais justa e eqüitativa da informação. Onde antes imperava a exclusão, hoje se debatem formas de inclusão social.

Modificam-se os cenários políticos, regionais e culturais dessa parte do planeta, com a predominância do desenvolvimento de estratégias compartilhadas, união de esforços e democratização da informação. A educação passa a ser uma área prioritária dos investimentos da União Européia. Proliferam as experiências de educação pelos meios, abrindo novas oportunidades de mercado e de formação pessoal e, de modo especial, as de educação a distância.

Essa nova modalidade de ensino vai requerer uma revisão dos sistemas de educação e formação para que atendam aos desafios da sociedade da informação.

As novas metas do processo educacional serão o desenvolvimento da qualidade, a formação de professores e a educação continuada.

As instituições escolares deverão abrir espaço às empresas, ou trabalhar em regime de parceria, oferecendo condições de aprendizagem através da prática. Isto, sem dúvida, irá refletir-se nos paradigmas que nortearão os futuros rumos da educação. 
O livre acesso à informação e o desenvolvimento de políticas que contemplem a formação profissional tornam-se imperativos desta nova sociedade.

O sonho de um mundo melhor, mais justo e harmonioso dependerá não apenas de uma distribuição democrática dos conhecimentos e informações, mas também da capacidade para produzi-los. Nesse contexto, a educação terá um papel fundamental e deve ser objeto de dis-

Resumo: $\mathrm{O}$ artigo discute as principais políticas e programas desenvolvidos pela União Européia (UE) no sentido de atender às necessidades impostas pela sociedade da informação. Traça um panorama dessa sociedade, impulsionada pelas tecnologias avançadas de informação e de comunicação. A autora observa o redimensionamento do mercado e dos espaços territoriais em virtude do processo de globalização, cujas novas configurações colocam o setor tecnológico em destaque. Diante deste quadro, comenta alguns aspectos dos principais relatórios e documentos elaborados pela União Européia, na década de 90 , bem como alguns programas criados especialmente para capacitar professores e estudantes, priorizando a educação para a sociedade da informação. Destaca que, se, por um lado, há um grande investimento no setor tecnológico, por outro, há a preocupação com as conseqüências sociais.

Palavras-chave: União Européia, sociedade da informação, tecnologia, políticas de educação cussão e atenção públicas.

Os responsáveis pelos sistemas educacionais, além de instrumentalizarem-se para acompanhar e oferecer as condições necessárias para a capacitação desse novo homem requerido pela sociedade da informação, devem, principalmente, empenhar-se para o desenvolvimento de valores éticos, voltados à construção de uma comunidade solidária, justa e crítica.

Abstract. The article discusses the main policies and programs developed by the European Union (EU) aiming at attending to the needs imposed by the information society. It traces a panorama of this society, propelled by advanced information and communications technologies. The author observes market redimensioning and the changes in territorial spaces as a result of the globalization process, and how the new configurations highlight the technological sector. Considering this, the author comments on a few of the aspects contained in the main reports and documents elaborated by the European Union in the 1990 's, as well as on a few programs created especially to capacitate teachers and students, giving priority to education and to the information society. According to the article if, on one hand, there are great investments being made in the technological sector, on the other great concern must be given to the social consequences of the process.

Key words: European Union, information society, technology, education policies. 